\title{
Nilai-Nilai Pendidikan Dalam Balian Tantulak Ambun Rutas Matei Bagi Masyarakat Hindu Kaharingan di Kota Palangkaraya Raya
}

\author{
Pranata \\ IAHN Tampung Penyang Palangka Raya \\ adityaken@yahoo.com
}

\begin{abstract}
The development of the times that are increasingly turning into an obligation for Hindu Kaharingan always to maintain and preserve a ceremonial tradition related to the teachings of their religion so that their generations do not forget the ceremony. Likewise, followers of the Hindu Kaharingan religion in Palangka Raya City who always carry out the balian tantulak ambun rutas matei ritual will always exist and develop to future generations of Hindu Kaharingan not forget it. The research was conducted in the city of Palangka Raya in 2020, using a qualitative descriptive method. Determining the informants used purposive sampling, considering that the informants were selected by researchers who carried out the research and understood the implementation of balian tantulak ambun rutas matei. The implementation of balian tantutulak ambun rutas matei is usually carried out after three days of death and burial. It is carried out by a base of 35 people and for 1 full day. The educational values that can be studied are educational values that can be explored in implementing the balian tantulak ambun rutas matei ceremony, namely Tatwa values, Moral values, and Upakara Psychomotor values. These values will be passed on to the next generation of Hindu Kaharingan so that the balian tantulak ambun rutas matei ceremony is not extinct.
\end{abstract}

Keywords: Value; Education; Balian Tantulak

\begin{abstract}
Abstrak
Perkembangan zaman yang semakin hari semakin berubah menjadi suatu kewajiban bagi pemeluk agama Hindu Kaharingan untuk selalu menjaga dan melestarikan suatu tradisi upacara yang berhubungan dengan ajaran agamanya, sehingga upacara tersebut tidak dilupakan oleh generasinya. Begitu juga dengan penganut agama Hindu Kaharingan yang berada di Palangka Raya yang selalu mengadakan ritual kematian khususunya ritual Balian Tantulak akan selalu eksis dan berkembang sehingga tidak akan terlupakan oleh generasi Hindu Kaharingan kedepan. Penelitian dilakukan di kota Palangka Raya tahun 2020, dengan menggunakan metode deskriptif kualitatif. Metode penentuan informan menggunakan porvosif sampling mengingat informan dipilih oleh peneliti yang melaksanakan penelitian, memahami dan mengerti tentang pelaksanaan ritual balian tantulak tersebut. Biasanya ritual ini dilaksanakan setelah 3 hari yang meninggal dunia dan dikuburkan. Dilaksanakan oleh basir berjumlah 3-5 orang dan dilaksanakan selama 1 hari penuh. Adapun nilai-nilai pendidikan yang bisa dikaji yaitu nilai-nilai pendidikan yang dapat digali dalam pelaksanaan upacara balian tantulak ambun rutas matei yaitu nilai Tatwa, Nilai Susila dan Nilai Psikomotorik Upakara. Nilai-nilai tersebut akan diwariskan kepada generasi penerus Hindu Kaharingan agar upacara balian tantulak ambun rutas matei tersebut tidak punah oleh perkembangan zaman.
\end{abstract}

Kata Kunci : Nilai; Pendidikan; Balian Tantulak 


\section{Pendahuluan}

Bangsa Indonesia adalah bangsa yang berpedoman pada adat, budaya dan religi. masa globalisasi berdampak akan terjadinya keadaan yang berubah cepat bagi kehidupan masyarakat, masyarakat Indonesia sebagai pemegang budaya Pancasila harus mempersiapkan diri dalam era masa kini, agar tetap bertahan pada budaya yang telah turun temurun diwariskan. Persiapan menghadapi persaingan dilakukan dengan cermat dan terarah, untuk menuju hasil yang diharapkan. Untuk itulah umat Hindu kaharingan harus selalu meningkatkan sumber daya manusianya agar mampu bersaing dan mempertahankan nilai-nilai yang terkandung didalam ajaran-ajaran ritual agamanya. Salah satu yang harus dipertahankan adalah ritual keagamaan dari upacara kelahiran sampai upacara kematian. Pelaksanaan ritual Keagamaan adalah bentuk kekayaan budaya di Kalimantan Tengah dan wajib kita pertahankan, dengan cara meningkatkan kualitas umat. Upacara keagamaan umat Hindu Kaharingan dapat dilihat mulai bayi berada di kandungan, kelahiran dan kematian sebagai jalan menuju Ranying Hatalla Langit, semuanya dilakukan melalui upacara Keagamaan.

Kalimantan Tengah dengan suku dayak di Pulau Borneo pada mulanya penganut ajaran agama helu/Kaharingan. Setelah integrasi pada tahun 1980 agama helu/kaharingan dikenal dengan Hindu Kaharingan. Khusus dalam ritual yang dilakukan oleh pemeluk Hindu Kaharingan tentunya mempunyai kekhasan tersendiri berdasarkan tradisi yang dijalankan oleh suku yang berada di Pulau Kalimantan ini. (tradisi dalam pelaksanaan upacara ciri khas ritual agama Hindu Kaharingan).

Upacara Ritual Keagamaan merupakan kewajiban bagi umat Hindu Kaharingan yaitu ritual Kematian (Pitra Yadnya). firman Ranying Hatalla dalam Kitab Suci Panaturan pasal 28 ayat 30 yaitu :

Kabantengan ewen sintung due ije sua-sual, jawab-jawab, te salenga dumah Ranying Hatalla hayak Ie Halawu rawei, kuae Ela gilan tingang ketun sintung due, basa bitim Raja Bunu uka ikau mandung hakatawan, panakan ayum dapit jeha, puna akan bagin matei; te nah buku AKU malaluhan akam bawi ije jatun bara aseng ngangkanae.

Artinya

Disaat mereka berdua saling betengkar, tiba-tiba saja RANYING HATALLA memperlihatkan dirinya seraya berfirman ; kalian berdua tidak perlu berbuat seperti itu dan kini KU ingatkan engkau Raja Bunu bahwa manusia dari keturunanmu nanti telah KU kehendaki akan kembali kepadaKU melalui kematian, dan itulah sebabnya AKU berikan untukmu seorang perempuan yang belum bernyawa. (Majelis Besar Agama Hindu Kaharingan, 2009:80)

Berdasarkan ayat kitab suci panaturan tersebut jelas bahwa bagi manusia yang mendiami pantai danum kalunen (dunia) ini maka nantinya ia akan kembali kepada Ranying Hatalla melalui kematian. Bagi pemeluk agama Hindu Kaharingan bahwa upacara Balian Tantulak Ambun Rutas Matei oleh masyarakat Hindu Kaharingan di Kota Palangka Raya adalah suatu upacara yang sudah mentradisi dalam rangkaian upacara kematian sehingga menjadi suatu tradisi yang melekat dan kewajiban yang harus dijalankan oleh penganut agama Hindu Kaharingan.

Meninggal dunia, berarti terputusnya hubungan dengan dunia dan kembali ke alam baka. Kematian merupakan sebuah takdir Ranying Hatalla Langit untuk kembalinya setiap mahluk hidup hidup termasuk manusia, dengan batasan oleh-Nya dalam hal umur. Menurut pandangan Preusz akan ritus kematian bahwa anggapan komponen ritus yang terpenting di dunia yaitu ritus yang berhubungan dengan kematian. Kemudian preusz menyatakan terhadap konsep manusia mengenai kehidupan dan ajal/maut kebenarannya terjadi dan diciptakan manusia berdasarkan ritus kematian sebagai awalnya 
(Koentjaraningrat,1987:69). Selanjutnya Van Genep mennyatakan tentang ritus dan upacara religi secara luas pada dasarnya merupakan kegiatan memunculkan kembali kekuatan kehidupan bersama berbagai warga masyarakat (Koentjaraningrat, 1987:74). Surayin (2004:2) mengungkapkan agama Hindu yang yakin dan percaya adanya roh yang masih hidup setelah badan kasar mengalami kematian, mempunyai ritual khas dalam pelaksanaan jazad seseorang yang kembali pada Hyang Widhi disebut dengan PITRA YAJNA yang didasarkan kepada tingkat dan kekedudukan orang tersebut yang bernilai “ Desa-Kala-Patra”.

Persembahan pada leluhur (pitra) dalam kitab Veda adalah kewajiban wajib dilaksanakan dengan ketulusan. Titib (2001:225) menyatakan ajaran suci Veda disamping mengajarkan menyerahkan diri pada Tuhan, sang dewata, juga diajarkan memberikan persembahan pada leluhur, yang hakikatnya para leluhur adalah manisfestasi sang Dewata. Setiap yang lahir sudah merupakan takdir akan mati. Dasarnya bahwa manusia mempunyai badan kasar atau disebut dengan jasmani, badan ini dikatakan mati (meninggal) jika nyawanya hilang. Dalam ajaran agama di Kalimantan Tengah yang disebut Hindu Kaharingan dikatakan pada Kitab Panaturan pasal 29 ini menuturkan tentang Ranying Hatalla Langit memperlihatkan dirinya di lewu Bukit Batu Nindan Tarung untuk mengajarkan, menasehati serta berpesan kepada Raja Bunu. bahwa nantinya raja bunu dan anak keturunannya akan mengisi alam semesta yang disebut kehidupan dan akan kembali kepada Ranying Hatalla melalui kematian".

Berdasarkan pasal 29 ayat 8 ini menyatakan bahwa kematian adalah takdir dari Ranying Hatalla Langit sebagai jalan proses bagi kembalinya kepadaNYa pada waktu yang sudah ditetapkan Ranying Hatalla. Seperti apa yang dinyatakan oleh Van Genep bahwa "upacara adalah merupakan inisiasi kehidupan". Senada dengan Van Genep, Crawley dalam bukunya Tree of Life (1905) yang menguraikan teorinya tentang "Masa Krisis Dalam Hidup Individu". Teori itu menguraikan, proses daur hidupnya, ada saat terpenting bagi sesorang, ketika seseorang sakit atau tertimpa musibah, pada saat itu sesorang akan melakukan perbuatan dalam memperkuat imannya, yang dilakukannya dengan ritual (Koentjaraningrat, 1987:197).

Ritual kematian Balian Tantulak Ambun Rutas Matei bagi masyarakat Hindu Kaharingan selain sebagai upacara kematian yang dilakukan secara turun temurun, juga mengandung makna yang mendalam dalam menjalani kehidupan di dunia, terutama makna pendidikan yang terdapat di dalam pelaksanaan ritual tersebut, agar generasi Hindu Kaharingan ke depan bukan hanya melaksanakan ritual nya saja melainkan juga dapat mengetahui makna atau nilai-nilai pendidikan yang terdapat didalam ritual keagamaan tersebut. Belum banyak penelitian yang khusus membahas tentang upacara Balian Tantulak ambun Rutas Matei, Mariatie (2019) membahas Balian Tantulak Ambun Rutas Matei yang difokuskan dalam persfektif Hukum Hindu, dengan tujuan bahwa upacara tersebut intinya mampu mengembalikan keimbangan mistis, terjauhkan dari bahaya serta membuang semua kesialan pada keluarga yang ditinggalkan.

Berdasarkan dari beberapa pandangan diatas, dan apabila melihat dari perkembangan zaman yang semakin hari semakin berubah, maka merupakan suatu kewajiban bagi pemeluk agama Hindu Kaharingan untuk selalu menjaga dan melestarikan suatu tradisi upacara yang berhubungan dengan ajaran agamanya, sehingga upacaraupacara tersebut tidak akan hilang dan dilupakan oleh para generasinya, begitu juga dengan ritual kematian ini selalu dilaksanakan oleh penganut agama Hindu Kaharingan khususnya yang berada di Kota Palangka Raya akan selalu eksis dan berkembang sehingga tidak akan terlupakan oleh generasi Hindu Kaharingan kedepan. Agar upacara Tantulak Ambun Rutas Matei ini tidak akan lenyap oleh berkembangnya zaman, untuk itu peneliti 
sangat tertarik untuk mengkaji Nilai-Nilai Pendidikan Dalam Balian Tantulak Ambun Rutas Matei Bagi Masyarakat Hindu Kaharingan di Kota Palangka Raya .

Fokus masalah dalam penelitian ini adalah tentang 1) Pelaksanaan ritual tantulak ambun rutas matei, 2) Nilai-nilai pendidikan yang terdapat didalam pelaksanaan ritual Tantulak ambun rutas matei. Tujuan penelitian yaitu mengetahui tentang pelaksanaan ritual tantulak ambun rutas matei dan nilai-nilai pendidikan apakah yang terdapat dalam ritual tantulak ambun rutas matei masyarakat Hindu Kaharingan di kota Palangka Raya. Tujuan ini dicapai untuk menambah wawasan dan pendokomentasian kekayaan khasanah budaya bangsa untuk di wariskan secara turun temurun agar tidak punah oleh perubahan zaman. Diharapakan juga bahwa hasil penelitian dapat memberi sumbangsih kepada ilmu pengetahuan khususnya di bidang keagamaan dan pendidikan Hindu Kaharingan dan juga bagi masyarakat luas.

Manfaat penelitian adalah diharapkan memberikan kontribusi berupa hasil penelitian dalam melestarikan budaya bangsa khususnya dalam pelaksanaan ritual balian tantulak ambun rutas matei serta memberikan pengetahuan tentang nilai-nilai pendidikan yang terdapat dalam pelaksanaan ritual balian tantulak ambun matei, sehingga generasi ke depan bukan hanya mengetahui bentuk pelaksanaannya saja melainkan juga mengetahui tentang nilai-nilai pendidikan yang ada dalam ritual tersebut.

Terdapat beberapa relevansi terhadap penelitian yang pernah dilakukan, seperti penelitian yang dilakukan oleh Etika (2018) yang berjudul prosesi ritual kematian umat Hindu Kaharingan suku Dayak Dusun di Kabupaten Barito Utara. Penelitian ini samasama meneliti tentang ritual kematian bagi umat Hindu Kaharingan, tetapi memiliki perbedaan yang karena ritual kamatian Hindu Kaharingan dilakukan sesuai dengan daerah masing-masing. Penelitian ini menganalisis pelaksanaan ritual kematian di Barito Utara, baik dari segi pelaksanaannya sampaikan kepada sarana dan prasarana yang digunakan didalam ritual kematian bagi umat Hindu Kaharingan

Penelitian Pranata (2008) dengan judul Studi Tentang Upacara Kematian Menurut Agama Hindu Kaharingan (Filosofis Habukung) Di Desa Pemantang Kecamatan Mentaya Hulu Kabupaten Kotawaringin Timur dimana dari hasil penelitian tersebut mengekplorasi dan menganalisis tentang upacara kematian (filosofis Habukung) di desa Pematang Kecamatan Mentaya Hulu kabupaten Kotawaringin Timur. Hubungan dengan penelitian yang dilakukan oleh peneliti adalah sama-sama berhubungan dengan upacara kematian menurut agama Hindu Kaharingan hanya berbeda pada segi tempat dan bentuk upacara.

Penelitian yang dilakukan oleh Santang (2019) yang berjudul tradisi upacara basiwah di desa Pendreh. Penelitian ini juga meneliti tentang ritual kematian umat Hindu Kaharingan khususnya di desa Pendreh kabupaten Barito Utara, dimana dalam penelitian ini memfokuskan tentang pelaksanaan dari ritual Basiwah.

Teori dalam penelitian ini menggunakan teori fungsionalisme dan teori nilai. Teori fungsionalisme merupakan pendekatan sistematik dalam ilmu sosial budaya, pendekatan sistematik dilihat dari pandangan dimana teori fungsionalisme mengakui adanya perubahan bagian dari sebuah system, dan akan mengakibatkan perubahan pada system yang lain, artinya teori ini membahas sebab akibat yang menjadi inti mekanisme suatu system sehingga dalam analisis teori fungsionalisme memberikan pemahaman tentang halhal yang menonjol pada waktu atau peristiwa tertentu. Ritzer (2004:23), menyatakan bahwa teori fungsional memandang semua pranata sosial dalam masyarakat tertentu memiliki fungsi positif dan negatif.

Ritzer (2004:123) Tokoh yang penggagas teori Struktural fungsional adalah Talcott Parsons yang berasumsi bahwa masyarakat dipandang sebagai sistem didalamnya terdapat bagian-bagian sistem yang bagian tersebut mempunyai fungsi untuk mencapai keseimbangan dalam masyarakat. Dalam teori fungsional structural Parsons ini secara 
sederhana adalah sebuah teori untuk pemahaman tentang masyarakatnya didasarkan pada system organik. Fungsional merupakan melihat masyarakat sebagai suatu system dari beberapa bagian yang saling berhubungan satu sama lainnya.

Menyimak dari teori fungsional struktural dalam penelitian ini sangat membantu untuk menginterpretasikan atau memahami pemahaman masyarakat Hindu Kaharingan dalam kontek ritual tentang komponen. Komponen yang dimaksud antara lain para tokoh agama, Basir, dan anggota masyarakat sebagai pelaksana termasuk sarana upacara dan simbol-simbol yang dipergunakan. Dalam pelaksanaan ada beberapa kesepakatan yang harus dilakukan oleh komponen-komponen sesuai dengan fungsinya masing-masing seperti hubungan dengan kepercayaan agama Hindu Kaharingan yang disesuaikan pada tempat, waktu dan keadaannya tentunya sudah menyatu dengan alam lingkungannya. Oleh sebab itu upacara balian tantulak ambun matei menurut keyakinan umat Hindu Kaharingan di kota Palangka Raya adalah suatu upacara yang dilakukan pada ritual kematian tiga (3) hari setelah proses pemakaman. Untuk menjelaskan tentang arti dan makna yang terkandung di dalam pelaksanaan upacara Tantulak Ambun Rutas Matei tersebut selain unsur-unsur dalam pelaksanaannya maupun sarana upacara yang mempunyai arti simbolik baik berupa benda ataupun kata-kata/ungkapan yang menjadi acuan gagasan yang memiliki arti tersendiri bagi masyarakat Hindu Kaharingan. Dalam upacara tersebut fungsi dan makna upacara sangat diharapkan kesakralannya.

Teori nilai adalah menyangkut sikap manusia untuk menyatakan baik atau jelek, benar atau salah dan diterima atau tidak, dengan demikian manusia dihadapkan kepada pemberian konfirmasi mengenai sejauh mana manfaat dari objek yang dinilainya. Menurut Jujun S. (2003) menyatakan bahwa istilah aksiologi diartikan sebagai teori nilai, berkaitan dengan fungsi pengetahuan didapat secara teori, aksiologi dibagi kepada tiga komponen, yang terdiri dari Moral Conduct, Esthetic Expression dan Sosio Political Live.

Berdasarkan dari ketiga kriteria diatas, dalam perkembangan ilmu pengetahuan dan teknologi akan selalu berhadapan kepada ketiga kriteria tersebut. Dimana pengtahuan dan teknologi baru akan terus dihadapkan kepada kemanfaatan tindakan moral apakah pengetahuan dan teknologi tersebut dapat dipertanggung jawabkan dari segi moral dan kemanusiaan. Nilai merupakan suatu yang abstrak, tidak terlihat, bisa dipikirkan, dihayati dan dipahami. Nilai juga dikaitkan berupa harapan, cita-cita, keyakinan dan yang bersifat batiniah, menilai artinya menimbang, yaitu aktivitas manusia yang membandingkan sesuatu untuk menentukan keputusan. Memperhatikan dari teori nilai dalam penelitian ini, yaitu untuk mengkaji tentang nilai-nilai pendidikan agama Hindu yang tedapat dalam ritual tantulak ambun rutas matei masyarakat Hindu Kaharingan kota Palangka Raya..

\section{Metode}

Penelitian ini adalah penelitian sosial dengan pendekatan kualitatif dengan survey. Penelitian ini juga menggunakan metode deduksi yaitu cara untuk mendapatkan pengetahuan secara ilmiah yang didasarkan dari pengamatan atas masalah yang bersifat umum kemudian disimpulkan menjadi bersifat khsusus. Hal ini dilakukan bertujuan untuk mengetahui sikap dan tingkah laku masyarakat dalam menghayati atau mamaknai ritual balian ambun rutas matei bagi umat Hindu Kaharingan. Waktu penelitian dilakukan pada bulan juni-juli 2020, lokasi penelitian di kota Palangka Raya. Metode penentuan informan menggunakan metode purposive sampling mengingat informan dipilih oleh peneliti yang melaksanakan penelitian, memahami dan mengerti tentang pelaksanaan balian tantulak ambun rutas matei. Informan yang di dipilih yaitu Basir Upu, ketua MD-AHK Kota Palangka Raya, tokoh umat Hindu Kaharingan.

Metode pengumpulan data dimulai dengan tahapan observasi, wawancara mendalam dan teknik dokumentasi. Metode analisis data dalam penelitian ini adalah 
dengan menggunakan deskriptif kualitatif. Analisis sesungguhnya sudah dilakukan sejak diadakan observasi lapangan, yang hasilnya berupa rencana penelitian, khususnya latar belakang dan rumusan masalah. selajutnya data yang dicari dalam penelitian secara menyeluruh sebenarnya sejalan dengan proses wawancara dan hasil pengamatan. berikutnya data yang sudah ada dicermati sebagai bahan untuk menyusun acuan laporan tersebut. Di dalam uraian yang membahas permasalahan tercermin analisis data, tidak saja dari susunannya, tetapi juga dari penafsirannya yang penulis coba lakukan dengan mengacu pada pendapat para ahli dan teorinya.

Dalam pengumpulan data dilakukan penyesuaian terhadap data wawancara yang belum berstruktur, dan disajikan data analisis kualitatif. Analisis deskriptif yaitu membuat telaah yang bersifat obyektif berdasarkan data dari berbagai pustaka ataupun data lain dilapangan, maka kegiatan selanjutnya melakukan analisis data dengan melakukan reduksi data, data disajikan secara deskriptif dan kronologis, dan melakukan penarikan kesimpulan dengan melakukan penafsiran mengenai nilai-nilai pendidikan Hindu yang termuat dalam ritual balian tantulak ambun rutas matei.

\section{Hasil dan Pembahasan}

\section{Pelaksanaan Balian Tantulak Ambun Rutas Matei}

Setiap yang lahir akan kembali padaNya, tidak ada yang abadi didunia ini. Dasarnya untuk seseorang yang mempunyai badan jasmani tentunya ia akan mati jika ia tidak bernyawa. Kitab suci Panaturan pasal 29 ayat 8 yaitu :

Kuan Ranying Hatalla Langit tinai, Pama ketun handiai te Raja Bunu Palus kakare garing tarantangmuh, Ilaluhan manyuang pantai danum kalunen, Amun jadi umbet katika ije inukas awiKu

Akan harian andau, ikau induangKu haluli Hije AKU, hayak dia mahalau pampatei.

Artinya

Kembali Ranying Hatalla langit berfirman Walaupun Raja Bunu Dan semua anak keturunanmu Diturunkan kealam kehidupan dunia Apabila telah tiba saatnya yang telah aku kehendaki dan aku tetapkan nanti Engkau akan AKU ambil kembali tidak melalui kematian. (Majelis Besar Agama Hindu Kaharingan, 2009:83)

Ayat diatas, menyatakan bahwa pada saat yang ditakdirkan oleh Ranying Hatalla,

maka ia akan kembali melalui proses kematian. Semuanya akan kembali tanpa memandang kaya atau miskin, tidak ada pilih kasih kelak pasti menuju ke arah kematian sesuai waktu dari takdirnya. Upacara kematian khususnya upacara Balian Tantulak Ambun Rutas Matei merupakan suatu upacara sakral dan banyak mengandung makna-makna simbolik didalam palaksanaanya maupun yang melatar belakangi dari pelaksanaan upacara tersebut. Ritual tersebut selalu dilaksanakan oleh Umat Hindu Kaharingan khususnya di Kota Palangka Raya jika ada anggota keluarga yang meninggal dunia. Upacara ini merupakan kewajiban bagi seluruh umat Hindu Kaharingan, sesuai firman Ranying Hatalla pasal 56 ayat 1 sampai 120 dalam kitab suci Panaturan tentang Bawi Ayah Nantuajar Auh Talatah Nantulak Ambun Rutas Matei.

Latar belakang diadakan Balian Tantulak Ambun Rutas akibat kematian bagi masyarakat Hindu Kaharingan, menurut Parada (Ketua MD-AHK Kota Palangka Raya) mengungkapkan, latar belakang dari diadakan upacara tersebut adalah berdasarkan kepada firman Ranying Hatalla Langit yang tertuang didalam Kitab Suci Panaturan, selanjutnya hal ini menjadi sebuah kewajiban bagi seluruh umat Hindu Kaharingan untuk melaksanakan upacara tersebut sebagai bentuk penghormatan bagi yang meninggal dunia supaya nantinya sampai kepada Ranying Hatalla Langit sebagai jalan awal sebelum pelaksanaan upacara Tiwah. Basir Upu Osoh T.Agan, menyatakan yang melatarbelakangi 
pelaksanaan upacara Balian Tantulak ambun Rutas Matei adalah berdasarkan pada firman Ranying Hatalla langit kepada Raja Bunu di pantai Danum Sangiang, dimana pada saat itu Ranying Hatalla langit memerintahkan kepada Bawi Ayah untuk turun ke Pantai danum kalunen (bumi) mengajarkan anak keturunan Raja Bunu tentang upacara-upacara termasuk upacara kematian yang merupakan jalan untuk kembali dan menyatu kepada Ranying Hatalla Langit, seperti yang telah disampaikan sebelumnya pada saat dilaksanakan upacara Tiwah Suntu di Lewu Bukit Batu Nindan Tarung. Berdasarkan keterangan diatas, maka upacara Balian Tantulak Ambun Rutas Matei adalah ritual wajib bagi umat Hindu Kaharingan, jika ada kematian yang dialami oleh keluarganya. Kewajiban ini tertuang pada Kitab Suci Panaturan didasarkan atas firman Ranying Hatalla langit sebagai tuntunan bagi umat Hindu Kaharingan didalam menjalani kehidupannya di dunia ini. Pelaksanaannya didasarkan pada upacara yang dilaksanakan di pantai danum sangiang berupa contoh pelaksanaan ritual Tiwah kepada Raja Pampulau Hawun yang kembali disampaikan Bawi Ayah untuk semua anak keturunan dari Raja Bunu dibumi sebagai cikal bakal dan contoh untuk dilaksanakan.

Mengapa ritual Balian Tantulak Ambun Rutas Matei dilaksanakan pemeluk agama Hindu Kaharingan, Menurut Parada, akibat dari kematian tersebut terjadi pali atau sial dalam kehidupan jika ada keluarga yang meninggal dunia. Sial pali belum (kesialan dalam hidup) akibat kematian, semua keluarga berduka cita, memulkan rasa kesedihan, kekacauan pikiran sehingga tidak mampu memikirkan sesuatu, maka untuk membuang sial pali belum itu, dilaksanakanlah ritualBalian Tantulak Ambun Rutas Matei .

Sesuai dengan pendapat diatas, kitab Suci Panaturan pasal 56 ayat 5 yaitu :

Kapali ije ingkeme awi uluh belum,

Awi tagal atun pampatei bara marak ewen, Jite ije mawi ewen te barutas,

kare gawi gawian uras dia tau sanunuh, basial bara kulae; amun ewen satiar bausaha dia tau baharui pandinue, jituh ije inulak irasihe, ingabuahe, uka akan ije belumtau sanang mangat, jatun taluh tau manderoh itung huange jetuh gawi ije inyewut Balian Tantulak Ambun Rutas Matei

Artinya

Pantangan yang dirasakan oleh manusia yang hidup Oleh sebab adanya kematian diantara mereka Itu yang menyebabkan mereka sial dan segala pekerjaannya kurang sempurna dan kurang berhasil Sial melanda keluarganya, kalau mereka berusaha Tidak mendapatkan penghasilan Inilah yang harus dibuang, disucikan agar mereka yang hidup Mendapatkan suatu ketenangan, tidak ada yang menganggu pikirannya Pelaksanaan inilah yang disebut Balian Tantulak Ambun Rutas Matei (Majelis Besar Agama Hindu Kaharingan, 2009:425).

Sial dan pantangan-pantangan didalam kehidupan yang diakibatkan oleh kematian inilah yang harus dihilangkan atau disucikan kembali sehingga bagi keluarga yang ditinggalkan mampu bangkit kembali dari rasa kesedihan akibat kehilangan, mampu bekerja kembali untuk mencari nafkah hidupnya, mampu berpikir dengan baik lagi tidak terlalu hanyut didalam kesedihan. Pelaksanaan ritual Balian Tantulak Ambun Rutas Matei adalah proses mengantarkan almarhum ke alam lain yaitu disebut Lewu Bukit Nalian Lanting, Rundung Kereng Naliwu Rahan, almarhum akan tinggal bersama Balu Indu Rangkang Penyang yang bertempat pada batang danum Baras Bulau, Guhung Sating Malelak Hintan, menunggu apabila pihak keluarganya dapat melaksanakan ritual Tiwah.

Ritual Balian Tantulak Ambun Rutas Matei, dilaksanakan sesudah hari ketiga upacara Penguburan dilaksanakan. pelaksanaan upacara Balian Tantulak Ambun Rutas Matei, terlebih dahulu pihak keluarga berkonsultasi dengan pimpinan basir (basir Upu) tentang hal-hal yang dipersiapkan oleh pihak keluarga duka. Wawancara dengan basir upu 
Osoh T Agan, mengungkapkan bahwa yang mesti dipersiapkan pihak keluarga duka yaitu: yang utama siapa basir yang akan melaksanakan ritual tersebut, disepakati jumlahnya berapa orang biasanya minimal 3 maksimal 7 orang basir. Perlengkapan lainya akan disampaikan oleh basir yang melaksanakan karena perlengkapan ritual tersebut cukup banyak yang harus dipersipakan, dan akan dipandu oleh basir dalam mempersiapkannya. yang utama perlengkapannya yaitu katil, garantung atau gong, macam-macam sanggar kambungan, sangku, pisau, apar, amak pasar, bendang, bendera, Ranying Pandereh Bunu, sirih, giling pinang, patung rotan, tangkawang papas, salentup, tambak, buah kelapa, pakaian liau haring kaharingan, sisir, minyak kelapa, cermin, kain panjang, macam-macam ketupat, telur ayam kampong, hewan korban berupa ayam, babi. semuanya dipersiapkan sebelum ritual dimulai, dan akan diapndu oleh basir agar lengkap dan tidak kurang

Setelah sarana dan pembicaraan tentang siapa yang memimpin upacara selesai, setelah waktu yang ditentukan maka dilakukan penjemputan Basir. Berdasarkan hasil wawancara dengan Basir Tambang didalam penjemputan Basir ke tempat upacara Balian tantulak ambun rutas matei dilaksanakan ada tata cara dan aturannya, pada hari yang ditentukan maka keluarga yang sedang dilanda duka melakukan penyemputan Basir dari rumah basir. Waktu berangkatnya Basir disepakati, sesuai arahan Basir tersebut. Setelah itu mereka keluar rumah, pihak keluarga yang bertugas menjemput membawa barangbarang basir berupa Katambung dan barang milik Basir. Setelah sampai rumah tempat pelaksanaan ritual, sebelum masuk, keluarga duka mengadakan pembersihan/pensucian Basir yang datang dengan menggunakan dawen sawang gagar (Daun Andong yang sudah jatuh) dan danum nyanyah behas (air cucian beras). Diharapkan dapat melepaskan hal-hal buruk yang bisa merusak ritual pada saat perjalanan para Basir, sehingga hal tidak baik bisa terlepas dan para Basir dapat melaksanakan ritual dengan baik.

Selanjutnya Basir Upu Osoh T. Agan, mengungkapkan bahwa pelaksanaan ritual Balian Tantulak untuk kematian dilaksanakan seharian dan selesai di hari berikutnya. pelaksanaan ritual akan segera dilaksanakan apabila perlengkapan untuk ritual telah di lihat Basir dan sudah lengkap, kemudian seluruh Basir sudah menyantap makanan yang disediakan oleh keluarga duka. Sebelum Balian dilaksanakan, pihak keluarga melakukan ritual manyaki mamalas Basir menggunakan darah ayam selanjutnya mengikatkan lamiang bua garing belum pada semua Basir. Khusus Basir Upu diikatkan sebuah emas dan uang logam.

Ritual dimulai Basir Upu melaksanakan manawur, yang bertujuan untuk memberitahukan kepada sangiang bahwa mereka sedang melaksanakan ritual Tantulak Ambun Rutas Matei, kemudian Basir melanjutkan Balian Nantilang Liau. Balian ini Nantilang Liau sebagai balian pembuka dengan mantra-mantra seperti :

i i i i i i lila lilang liau buang mate

Sambil ngantau, nantuhe pangambun Nihau kutuh ulang pajambilei Liau lunuk awang taheta batipas pantang Kamban baringen bahua bagetu sangkabilae Timpun raja awang parariup bihing Bulau sangkalemu mantap tasalae Bagatung petak sintel habalambang tambun Kahem nyalung kapanduya, limpar Guhung jampena .........

Artinya

Singkirkanlah ke kiri dan ke kanan sejenak

Para arwah yang telah lama meninggal dunia

Begitu juga para arwah yang baru saja Meninggal dunia

Roh para orang perempuan muda yang telah meninggal dunia bagaikan dirampas dari tengah keluarga telah lama badannya dikandung tanah Meninggal dunia bagaikan bahtera tenggelam ditengah samudera 
Basir Upu Osoh T. Agan, menyatakan tentang ucapan iiiiiiiii di awal dimulainya tandak Balian mengandung makna IA yang kuasa, merupakan awal dan akhir dari semuanya, yang bertujuan sebagai ucapan pembuka alam atas serta bertujuan untuk memuji Ranying Hatalla. Balian Nantilang Liau sudah selesai, dilanjutkan doa mantra Balian Manjung Tawur dan nyaluh tawur yang doa mantra seperti :

Ruhung-ruhung tamuei tawur lius nunjung taribangae,

Lentu kajan sawung ambun sikap mangkat pangasiring

Balua balai rampar bunu,

Bahajung Sali lintung tilap talawang

Eleh kilat basangkelang dawen pinang Sarayung lewu, usang liu basampele nyarak Bumbung katilambung nyahu.......

Nyandar sala lalangae lawin tambun pamalangkan pantar....

Artinya

Menderu-deru bunyi tawur mulai perjalannya

Terbang membumbung tinggi keatas Keluar dari balai rampar bunu Sali tilap talawang

Laksana petir dan halilintar tawur lewat Diantara daun pisang dan kelapa Perjalanan tawur menghampiri ujung tiang pantar

Setelah selesai, Basir istirahat sebentar, dan setelah siap semuanya dilanjutkan dengan Balian Mujan Balai, yaitu mantra tentang tujuan dan maksud dari datangnya tawur ditengah-tengah mereka para Sangiang. Khusus Balian Mujan Balai ada doa suci diucapkan basir menyesuaikan jenis ritual yang dilaksanakan. Mantra Balian Mujan Balai seperti:

Mujan Bangkang Balanga Tingang,

Nyamperai Tambun Repang Garantung,

Batu Sarakumpang Eawing, Tahan Liang Katihulun Amban

Mujan nutuh renteng tingang, nyahep luhing pating bungai,

Malapak kumpang duhung, tawur nyauh sapalangan tambang

Mujan Sangiang tabela, tende pandung kanumpuh bujang,

ruang batunjung tahan duhung garagan balai mihing

Artinya

Melewati guci balanga,

repang garantung

serta tempat menempati deretan guci

tawur turun dan tiba diantara para sangiang yang sedang duduk berkumpul di dalam ruangan balai

Tawur berada diantara para sangiang di tengah kelompok anak-anak, dewasa dan orang-orang tua pimpinan balai mihing

Balian Mujan Balai selesai, dilanjutkan Balian mendatangkan Talawang jambu Bahandang, dan Sangiang Duhung Mama Tandang dihadirkan pula menuju ketempat ritual. sangiang tiba di bumi menuju rumah ritual memasuki dan merasuk Basir, para sangiang melaksanakan pensucian yaitu melepaskan pengaruh buruk sial kematian dan segala pantangan-pantangan hidup kepada keluarga yang mengalami musibah kematian.

Kemudian Raja Duhung Mama Tandang yang sudah merasuki Basir mengucapkan ritual bagi orang yang meninggal. Ritual Balian ini sewaktu Raja Duhung Mama Tandang menuju kuburan (Bukit Pasahan Raung). Melalui ilmu dan kesaktianya maka terjadi pembicaraan antara Raja Duhung Mama Tandang dan almarhum yang meninggal (Liau Haring Kaharingan). Disanalah basir yang telah dirasuki oleh Raja Duhung Mama Tandang menyampaikan dan menjelaskan kepada Liau Haring Kaharingan bahwa ia telah meninggal dunia, meninggalkan lewu Injam Tingang. Setelah ia menyadari bahwa ia telah 
meninggal dunia, maka sangat sedih dan menangis kemudian menyampaikan bahwa teganya Riwut Peres (Penyakit/mara bahaya) telah mengambil nyawanya, sedangkan ia mau tetap tinggal bersama keluarganya. melihat kesedihan tersebut Raja Duhung Mama Tandang memberikan nasehat kepada almarhum, agar jangan bicara yang aneh-aneh cucuku, karena memang sudah janji dan takdir mu oleh Ranying Hatalla Langit, untuk kembali ke lewu tatau

Mendengar nasehat tersebut maka ia sadar ternyata ia betul meninggalkan dunia, ia menyucikan dirinya agar menghilangkan kesalahan dan perkataannya yang salah, membuang semua sial waktu di dunia. Setelah disucikan tersebut, maka ia terlihat terlihat bersih dan suci. Maka berangkatlah berdua menuju ke berbagai tempat guna mensucikan Liau Haring Kaharingan serta memohon untuk keluarganya yang disebut Tarantang nule mendapatkan harta kekayaan (Penyang Karuhei Tatau). Setelah itu berangkat lagi mereka menuju tempat-tempat khusus yang pernah ditempatinya sewaktu ia hidup, pada akhirnya mereka berdua tiba di tempat ritual berlangsung, dan menyampaikan agar semua keluarganya berkumpul, kemudian Liau Haring Kaharingan memberikan nasehat dan pesan agar keluarga yang di tinggalkan bisa hidup rukun, jangan berkelahi, bertengkar. Selanjutnya ia menyampaikan permintaan berupa giling pinang, rokok, makanan dan minuman sebagai permintaan terakhir kepada tarantang nule, maka serentak tarantang nule memberikan semua permintaannya. Berikutnya ia meminta untuk meneteskan minyak kelapa dirambutnya serta menyisir rambutnya agar bagus, bergantian seluruh keluarga dekat mengelus minyak kelapa ke rambut dan menyisir rambutnya (rambut yang di sisir disini sebagai simbol yaitu rambut basir upu yang dirasuki Liau Haring Kaharingan).

Kemudian ia memohon agar keluarganya bisa berdiri serta memegang tangannya karena ia ingin menganugrahkan sumber harta kekayaan berupa Kayun Penyang Karuhei Tatau sehingga keluarga yang ditinggalkan dapat sejahtera, sehat dan kaya. Setelah itu, ia keluar dari Basir dan berjalan menuju keluar kearah sarana yang digunakan bersama Raja Duhung Mama Tandang sewaktu berangkat yaitu Lasang Riwut kemudian terbang menjauh menuju tempat persingahan sementara (Lewu Bukit Nalian Lanting). dibuatkan rumah tempat tinggal almarhum menunggu dilaksanakan upacara Tiwah.

Setalah selesai Raja Duhung Mama Tandang menuju ke rumah tempat pelaksanaan ritual, dan menyampaikan kepada seluruh keluarga agar mentaati Pantangan-pantangan ritual tersebut, apabila melanggar pantangan, apa yang sudah disampaikan kepada mereka tidak akan berarti bagi kehidupan mereka. Kemudian dilanjutkan lagi dengan mantra Balian Pabuli Sangiang yaitu mengembalikan sangiang yang merasuk basir untuk keluar dan keluar dari rumah dengan membawa sesajen yang telah disiapkan. Pihak keluarga membawa berbagai ancak sesajen ke kuburan liau Haring Kaharingan, Balian Selesai dan Basir istirahat. Ritual ini biasanya selesai pada hari menjelang pagi. Pagi harinya semua Basir sudah siap, dilanjutkan Balian Paturun Sangiang. Menurut Basir Upu Osoh T. Agan, Balian ini bertujuan menyampaikan laluh lasang Sangiang yang bertugas serta menyampaikan pantangan. Pantangan dan larangan harus ditaati oleh anggota keluarga berupa makanan yang tidak bisa dimakan selama 3 (tiga) hari setelah pelaksanaan ritual balian tersebut berupa ikan majuhan, jantung pisang, buah botong, kancil, menjangan, rusa, pucuk rotan. dan untuk pantangan makanan selama 7 (tujuh) hari seperti babi hutan, ikan tatawun, ikan janjulung, ikan tampala, udang sungai kecil, tumbuhan paku, rebung bamboo, jamur pohon, jamur tanah, ikan saluang merah. Setelah pantangan tersebut diberitahukan, Basir melaksanakan Balian mengantarkan sangiang pulang (Balian Pabuli sangiang) dimana mereka pulang ketempatnya yang berada di Batang Danum Jalayan. Selesailah seluruh rangkaian upacara Balian Tantulak Ambun Rutas Matei. Basir kemudian diantar pulang kerumahnya oleh keluarga pelaksana upacara. 


\section{Nilai-Nilai Pendidikan dalam Upacara Balian Tantulak Ambun Rutas Matei}

Melihat dari perkembangan zaman yang semakin hari semakin berubah, maka merupakan suatu kewajiban bagi pemeluk agama Hindu Kaharingan untuk selalu menjaga dan melestarikan suatu tradirsi upacara yang berhubungan dengan ajaran agamanya, sehingga upacara-upacara tersebut tidak akan hilang dan dilupakan oleh para generasinya, begitu juga dengan upacara Balian Tantulak Ambun Rutas Matei ini yang selalu dilaksanakan oleh penganut agama Hindu Kaharingan di Kota Palangka Raya Provinsi Kalimantan Tengah akan selalu eksis dan berkembang sehingga tidak akan terlupakan oleh generasi Hindu Kaharingan kedepan. Pelaksanaan ritual Balian tersebut, tentunya memiliki makna yang mendalam yang harus digali sehingga benar-benar dapat dihayati dan dimengerti oleh seluruh pemeluk agama Hindu Kaharingan. Adapun nilai-nilai pendidikan yang terkandung didalam pelaksanaan ritual Balian tersebut dapat dilihat dari Nilai Kognitif (nilai Tattwa), Afektif (Nilai Susila) dan Psikomotorik (nilai Upakara).

\section{a. Nilai pendidikan Tattwa}

Nilai Pendidikan Tattwa dalam Upacara Balian Tantulak Ambun Rutas Matei masyarakat Hindu Kaharingan yakni berupa nilai ilmu pengetahuan yaitu mentranformasi nilai yang terkandung didalam ritual itu, berupa nilai ketuhanan, nilai kebaikan maupun nilai yang lainnya. Kitab Suci Panaturan didalam pasal 41 ayat 2 mengungkapkan ayat diatas terkandung nilai-nilai Tattwa yang terlihat saat keturunan Raja Bunu sudah melupakan firman Ranying Hatalla, melihat hal tersebut Ranying Hatalla berfiman untuk Raja Uju Hakanduang berangkat untuk mengajarkan kembali firman Ranying Hatalla kepada keturunan raja bunu, agar mereka kembali ingat dan tetap menjalankan ritual yang telah diajarkan. Melalui pelaksanaan Balian Tantulak Ambun Rutas Matei, dalam ritual kematian masyarakat Hindu Kaharingan kota Palangka Raya tentunya memberikan pemahaman tentang teknis pelaksanaan dan sarana dan prasarana yang digunakan didalam kegiatan ritual tersebut. Generasi Hindu Kaharingan kedepan akan tetap mengetahui dan menjalankan ritual tersebut, sesuai dengan ajaran leluhurnya.

Pengetahuan yang di dapat dari pelaksanaan ritual Balian Tantulak ambun Rutas Matei, menurut Parada, mengungkapkan bahwa tiap pelaksanaan balian ambun rutas matei, hendaknya generasi muda Hindu Kaharingan, agar serius memperhatikan dan memahami makna ritualnya, dengan mengetahui sarana dan prasarana yang harus dipersiapkan, tata letak sarana prasarana tersebut, bagaimana prosedur pelaksanaanya merupakan pengalaman pengetahuan langsung yang di dapat dari para basir dari melihat memperhatikan dan mendengarkan secara langsung tentunya akan mempermudah untuk mencerna dan memahami tentang ritual.

Basir Upu Osoh T. Agan mengungkapkan bahwa nilai kognitif atau pengetahuan dalam Balian Tantulak Ambun Rutas Matei mengandung nilai-nilai pendidikan yang harus terus dipertahankan oleh generasi Hindu Kaharingan. Pengetahuan tentang sarana dan prasarana yang digunakan, tata cara pelaksanaannya maupun pengetahuan akan pantangan yang tidak boleh dilakukan atau dimakan setelah pelaksanaan upacara tersebut, merupakan bekal bagi generasi untuk melaksanakan di kemudian hari. Nilai pendidikan tattwa atau ketuhanan dalam pelaksanaan upacara Balian Tantulak Ambun Rutas Matei berupa pengetahuan tentang nilai-nilai ketuhanan yang bersifat positif didalam menjalankan kehidupan. upacara kematian masyarakat Hindu Kaharingan tentunya terus berkembang dan bertahan sehingga tidak hilang ditelan zaman. Bahwa Ranying Hatalla telah menyampaikan firmannya kepada umat manusia di dunia, apabila saatnya tiba maka akan diambil kembali melalui proses kematian. Upacara untuk kembali tersebut diajarkan oleh Bawi Ayah di pantai danum kalunen (dunia). Pengetahuan inilah yang harus dimiliki oleh generasi Hindu Kaharingan agar terus eksis dengan menjalankan ritual dalam menjalani kehidupan. 


\section{b. Nilai Pendidikan Susila}

Nilai Susila dalam Balian Tantulak Ambun Rutas Matei adalah tentang nilai-nilai rasa bakti yang dilihat dari proses pelaksanaan upacaranya maupun sarana dan prasarananya. Nilai Susila merupakan wujud bakti yang tercermin pada awal sampai pada akhir ritual tersebut. Rasa bakti tersebut dengan berkumpulnya seluruh anggota keluarga didalam pelaksanaan upacaranya, dari pagi hari sampai dengan hari menjelang subuh semua keluarga berkumpul untuk mengiuti kegiatan upacara tersebut. Menurut Parada, Bakti juga simbolkan dalam kegiatan penyiapan sarana dan prasarana yang digunakan, semua anggota keluarga terlibat dengan penuh rasa bakti agar proses upacara balian tersebut dapat berjalan dengan baik, bakti juga merupakan suatu simbol cinta kasih dari keluarga yang ditinggalkan, untuk menunaikan ajaran suci bahwa meruapakan kewajiban untuk melaksanakan ritual Balian Ambun Rutas Matei tersebut, agar keluarga yang ditinggalkan dapat kembali beraktivitas seperti sedia kala, karena dengan dilaksanakan ritual tersebut maka segala sial akibat dari kematian tersebut akan dapat di sucikan Kembali.

Selajutnya basir Osoh T. Agan mengungkapkan bahwa nilai Susila tersebut melambangkan bakti dari anggota keluarga kepada anggota keluarga yang meninggal dunia, bahwa rasa cinta kasih tidak akan pernah hilang walau maut memisahkan, sehingga kewajiban suci anggota keluarga untuk menjalankan semua ritual dalam proses kematian tersebut wajib dilaksanakan sampai kepada pelakanaan upacara kematian tingkat akhir yaitu Tiwah Berdasarkan nilai Susila pada ritual Balian Tantulak umat Hindu Kaharingan adalah melambangkan nilai-nilai bakti, meliputi bakti kepada orang tua maupun kepada sesama, juga terutama bakti terhadap Tuhan serta bakti dengan Leluhur.

\section{c. Nilai Pendidikan Upakara}

Nilai upakara dalam upacara Balian Tantulak Ambun Rutas Matei umat Hindu Kaharingan yaitu berupa nilai-nilai positif yang ada tercermin didalam mempersiapkan berbagai sarana dan prasarana di dalam pelaksanaan upacara tersebut. Bagaimana seluruh anggota keluarga bersama-sama dengan basir sebagai pelaksana upacara mempersiapkan semua perlengkapan upacara dari yang terkecil sampai yang terbesar.

Menurut Parada, nilai upakara dalam upacara Balian Tantulak Ambun Rutas Matei tercermin pada saat mempersiapkan semua sarana dan prasarana yang wajib harus ada dan dipersiapkan dengan hati yang tulus iklas agar pelaksanaan Balian Tantulak Ambun Rutas Matei dapat berjalan dengan baik. dari mempersiapkan katil sampai kepada persiapan hewan korban semuanya harus selesai dalam jangka waktu tiga hari sebelum akan dilaksanakannya Balian Tantulak Ambun Rutas Matei pada hari ketiga sejak penguburan liau haring kaharingan. Adapun jumlah sarana dan prasaranan yang harus dipersiapkan biasanya berjumlah 26 (dua puluh enam) komponen

Selanjutnya Basir Osoh T Agan mengungkan bahwa nilai upakara dalam upacara Balian Tantulak Ambun Rutas Matei merupakan perwujudan dari nilai-nilai ketrampilan atau keahlian dalam mempersiapkan semua sarana dan prasarana upacara yang cukup banyak. dari mempersiapkan katil atau tempat duduk basir yang biasanya dibuatkan seindah mungkin, ketampilan untuk membuat segala bentuk katupat, membuat sangar timpung yang tentunya harus memiliki keahlian khusus. Dalam upacara tersebut, maka basir sebagai pelaksana upacara harus mempersiapkan segala sarana dan prasarananya dengan baik dan tidak boleh kurang, karena kalau kurang pasti akan berdampak negatif bagi semuanya. nilai upakara tersebut merupakan bentuk simbol cinta kasih sayang keluarga kepada liau haring kaharingan agar terlepas dari segala beban hidup dan kembali dengan tenang kepada Ranying Hatalla Langit. 
Sangatlah jelas bahwa upacara Balian Tantulak Ambun Rutas Matei bagi umat Hindu Kaharingan adalah Sakral dan suci, maka tidak boleh main-main didalam melangsungkan upacara tersebut karena banyak nilai upakara yang dapat digali dan harus diamalkan didalam menjalani kehidupan didunia. nilai-nilai upakara tersebut yang akan ditransfer kepada generasi muda Hindu Kaharingan sehingga nantinya upacara Balian Tantulak Ambun Rutas Matei yang sangat suci dan sakral tersebut tetap eksis dan bertahan.

\section{Kesimpulan}

Ritual Balian Tantulak Ambun Rutas Matei merupakan kewajiban bagi umat Hindu Kaharingan sesuai Kitab Suci Panaturan pasal 56 ayat 1 sampai 120 tentang Bawi Ayah Nantuajar Auh Talatah Nantulak Ambun Rutas Matei. bahwa proses dari pelaksaan upacara dari awal sampai akhir sudah diajarkan oleh Ranying Hatalla Langit melalui bawi Ayah. pelaksanaan upacara berlangsung selama 1 hari satu malam. di dilaksanakan oleh basir sebanyak 3 sampai 7 orang basir yang penting berjumlah ganjil. sedangkan sarana dan prasarana yang digunakan dalam pelaksanaan upacara Balian Tantulak Ambun Rutas Matei sebanyak 26 komponen yang wajib ada. Nilai-nilai pendidikan yang dapat digali dalam pelaksanaan upacara Balian Tantulak Ambun Rutas Matei yaitu Nilai Tattwa, Nilai Susila dan Nilai Upakara. Nilai-nilai tersebut yang akan diwariskan kepada generasi penerus Hindu Kaharingan agar Upacara Balian Tantulak Ambun Rutas Matei tersebut tidak punah oleh perkembangan zaman yang semakin dan terus berubah.

\section{Daftar Pustaka}

Etika, Tiwi. 2018. "Proses Ritual Kematian Umat Hindu Kaharingan Di Kabupaten Barito Utara." Jurnal Widya Katambung 7(2):34-52.

Jujun S., Suriasumantri. 2003. Filsafat Ilmu Sebuah Pengantar Populer. Jakarta: Pustaka Sinar Harapan.

Koentjaraningrat. 1987. Sejarah Teori Antropologi. Jakarta: Universitas Indonesia.

Majelis Besar Agama Hindu Kaharingan. 2009. Panaturan. Denpasar: Widya Darma.

Mariatie. 2019. "Upacara Tantulak Ambun Rutas Matei Pada Masyarakat Hindu Kaharingan (Perspektif Hukum).” Jurnal Belom Bahadat: Jurnal Hukum Agama Hindu 9(1):29-56.

Pranata. 2008. Studi Tentang Upacara Kematian Menurut Agama Hindu Kaharingan (Filosofis Habukung) Di Desa Pemantang Kecamatan Mentaya Hulu Kabupaten Kotawaringin Timur. Palangka Raya.

Ritzer, G. 2004. Sosiologi Ilmu Pengetahuan Berparadigma Ganda. Jakarta: PT. Raja Grafindo Persada.

Santang. 2019. "Tradisi Upacara Basiwah Dalam Masyarakat Hindu Kaharingan Desa Pendreh.” Jurnal Bawi Ayah 10(1):54-65.

Surayin, Ida Ayu Putu. 2004. Pitra Yajna. Surabaya: Paramita.

Titib, I. Made. 2001. Teologi Dan Simbol-Simbol Dalam Agama Hindu. Surabaya: Paramita. 